\title{
DIVISION VII: GALACTIC SYSTEM (SYSTEME GALACTIQUE)
}

\author{
PRESIDENT: Georges Meylan \\ BOARD: Gary S. Da Costa, Kenneth C Freeman, Ata Sarajedini, \\ David N. Spergel \& Patricia A. Whitelock
}

\section{Commission 33: Structure and Dynamics of the Galactic System Commission 37: Star Clusters and Associations}

The scientific interests of Division VII are concerned with the Galactic system. The two constituents of this Division are Commission 33 (Structure and Dynamics of the Galactic System) and Commission 37 (Star Clusters and Associations). Please refer to the reports of these two Commissions for the scientific highlights and list of major conferences in these scientific areas.

Study of the Galactic system involves a wide range of subjects and techniques, establishing bridges towards other Divisions and Commissions. For example, during the last decade, numerous studies investigated extra-galactic star clusters of all ages, with important cosmological implications. Consequently, the scientific fields covered by many other Divisions and Commissions are therefore of very significant interest to Divisions VII. In particular, astrophysicists with interests in the Galactic system may consider reading also the report of Commission 5: Documentation and Astronomical Data, Commission 7: Celestial Mechanics and Dynamical Astronomy, Commission 8: Astrometry, Commission 9: Instrumentation and Techniques, Commission 25: Stellar Photometry and Polarimetry, Commission 26: Double and Multiple Stars, Commission 27: Variable Stars, Commission 28: Galaxies, Commission 29: Stellar Spectra, Commission 30: Radial Velocities, Commission 34: Interstellar Matter, Commission 35: Stellar Constitution, Commission 36: Theory of Stellar Atmospheres, Commission 40: Radio Astronomy, Commission 44: Space and High Energy Astrophysics, Commission 45: Stellar Classification, and Commission 47: Cosmology.

Georges Meylan

President of the Division 